\title{
Link between Micro Credit on SMEs business Growth and Poverty Alleviating in Rural Sindh
}

\author{
Prof. Fayyaz Mahmood \\ Saudi Industrial Development Fund, \\ Ministry of Petroleum, \\ Industries, and mining, Riyadh, Saudi Arabia. \\ Dr.Nadeem Bhatti \\ Training Consultant \\ Human Resource Department \\ Saudi Industrial Development Fund \\ Saudi Arabia. \\ Dr.Anwar Ali Shah G.Syed \\ PVC-Sindh University Campus Dadu \\ Dr. Abdullah Sethar \\ Deputy Project Director, \\ Sindh Agricultural Growth Project ( Livestock Component) \\ World Bank Assisted, Government of Sindh, \\ Hyderabad-Sindh

\section{Faiz Muhammad Shaikh \\ -Larkana-Sindh-Pakistan} \\ Assistant Professor-SZABAC-Dokri
}

\begin{abstract}
The current research investigates the linkage between Micro credit on SMEs business growth and poverty alliviation in rural Sindh. Data will be collected from 300 respondents who used Micro credit by using the simple random sampling technique and data were analysis by using SPSS-21 version. It was revealed that micro credit increases employment and productivity or not is an empirical question which we will explore in this section. Consequently, the best way to reduce poverty is to deal with both problems: increasing productivity by creating employment and developing human capital. One way to increase the productivity of the poor is through broad-based economic growth.
\end{abstract}

Key Words: Micro Credit, Poverty, alleviation.

\section{Introduction}

Micro credit refers to making small loans available to the poor through schemes especially designed to meet the Poor's particular needs and circumstances. It has proven an effective and popular measure in the on going struggle against poverty, enabling those without access to lending institutions to borrow at bank rates, and start small business. The concept of Micro credit was pioneered by Dr.Mhuhammad Yunus, and first implemented in the Grameen Bank, Bangladesh. Subsequently, Grameen Bank replications have proliferated, and have proven effective in repeating the Micro credit miracle one vast and constantly increasing scale. Numerous schemes, in developing countries in particular, have now shown that micro credit can make a significant contribution to tackling poverty.

Micro means small, credit means the opportunity to borrow money. Micro credit is a small amount of money loaned to a client by a bank or other institution. Microfinance refers to loans, savings, insurance, transfer services, micro credit loans and other financial products targeted at low-income clients. Micro credit is a system where people in poor countries can borrow small amounts of money at low rates of interest even if they have little or no collateral. It works through small banks, which lend money to local people so that they can start businesses and earn their living. Micro credit and Micro finance have changed the lives of people and revitalized communities in the words poorest and also the richest countries. Micro credit has been changing the lives of people and revitalizing communities' worldwide since the beginning of time. Micro credit programs extend small loans to very poor people, for self-employment projects that generate income allowing 
them to care for themselves and their families (Micro credit summit). In Micro credit, more emphasis is on loans. Micro credit caters commercial needs of poor for enabling them to raise their income levels and improved standard of living. Micro credit means more emphasis on loans while micro finance also includes support service where you open up channels for thrift, market assistance capacity building, insurance, social and cultural programs. So where microfinance is credit plus, there Micro credit is "only credit". In this way,

In the writing, the terms microcredit and microfinance are regularly utilized conversely, however it is imperative to highlight the contrast between them in light of the fact that both terms are frequently confounded. Sinha (1998, p.2) states "microcredit alludes to little advances, while microfinance is suitable where NGOs and MFIs1 supplement the advances with other money related administrations (reserve funds, protection, and so forth)". Consequently microcredit is a segment of microfinance in that it includes giving credit to poor people, yet microfinance likewise includes extra non-acknowledge money related administrations, for example, reserve funds, protection, annuities and installment administrations (Okiocredit, 2005). 2. The History of Microfinance Microcredit and microfinance are moderately new terms in the field of improvement, first coming to unmistakable quality in the 1970s, as per Robinson (2001) and Otero (1999). Preceding then, from the 1950s through to the 1970s, the procurement of money related administrations by contributors or governments was chiefly as sponsored provincial credit programs. These frequently brought about high advance defaults, high loses and a failure to achieve poor rustic family units (Robinson, 2001). Robinson expresses that the 1980s spoke to a defining moment in the historical backdrop of microfinance in that MFIs, for example, Grameen Bank and BRI2 started to demonstrate that they could give little credits and investment funds benefits productively on an extensive scale. They got no proceeding with sponsorships, were economically financed and completely reasonable, and could accomplish wide effort to customers (Robinson, 2001). It was likewise as of now that the expression "microcredit" came to unmistakable quality being developed (MIX3 , 2005). The contrast amongst microcredit and the sponsored rustic credit projects of the 1950s and 1960s was that microcredit demanded reimbursement, on charging loan costs that took care of the expense of credit conveyance and by concentrating on customers who were subject to the casual area for credit (in the same place.). It was presently clear interestingly that microcredit could give expansive scale exceed productively

-Kakwani and Subbarao (1990) built up their own technique to gauge independently the effect of changes in normal wage and pay imbalance on neediness. The study analyzed past patterns in the conveyance and development of utilization and evaluated their relative effect on poor people and the ultra poor, after some time and crosswise over fifteen noteworthy conditions of India. National Sample Survey information for 197273, 1973-74, 1977-78 and 1983 was utilized. The numerical evaluations of the development and imbalance impacts on headcount proportion and destitution crevice proportion were gotten. The imbalance impact was certain in every one of the states amid the primary time frame (1973-74 to 1977-78). The lessening in destitution, which occurred in many states, was because of the high development rates, which more than adjusted for the unfriendly impacts of expanding disparities in this period. Notwithstanding, this circumstance changed in the second time frame (1977-78 to 1983). In every one of the states, the poor profited relatively more than the non-poor. On the premise of its outcomes, the study endeavored to dissect the administration's procedure for lessening the frequency of neediness taking into account a blend of quickened general development and focused on direct against destitution mediations. For the reason, the study considered the potential roundabout part of farming and assembling, and the commitment of direct hostile to neediness programs. The patterns in social part consumptions, and their results for neediness lessening were likewise broke down.

-Ravallion and Huppi (1991) developed the examination of total destitution in Indonesia as did by Ravallion and huppi (1989). This study utilized certain parts of the "destitution decay technique" to toss light on the potential for future decreases in neediness in Indonesia. It utilized the 1987 results for Indonesia to appraise the versatilities of neediness to any future distributionally unbiased development in mean utilization. It was found that the 1987 development flexibilities were considerably higher than those of 1984 . These higher development flexibilities of neediness combined with the higher utilization development rates suggested expanding destitution mitigation through any distributional impartial development after 1987. The concentrate then assessed the destitution measures coming about because of 5 and 10 percent increments in mean utilization after 1987, expecting first that the 1987 Lorenz bend held, and second, that imbalance expanded to its 1984 level. It was registered that the total head-number file tumbled from 21.7 percent to 19.3 percent as an aftereffect of a distributional impartial 5 percent expansion in genuine utilization per capita after 1987. Assuming, nonetheless, the same increment in the mean were connected with an arrival to the less fair 1984 Lorenz bend, the subsequent headcount file was assessed at 21.1 percent, just somewhat lower than its 1987 level.

\section{Data Collection Methodology}

$2930 \mid P$ a g e

A u gust 2016

council for Innovative Research

w w w. cir w or ld. com 
Data will be collected from 200 respondents who used Micro credit by using the simple random sampling technique and data were analysis by using SPSS-16-5 version. Interviews of farmers /growers, officers of micro credit, office public and private supporting services, Institutions and other professionals were conducted by using structured interview.

Table1. Thesize-class Structureof Sukkur District

\begin{tabular}{|l|c|c|c|l|l|l|l|}
\hline & \multicolumn{2}{|l}{ Numberofenterprises } & \multicolumn{3}{l|}{ Shareportionin\%Economic } \\
\hline & Small & Medium-sized & Large & Total & Small & Medium-sized & Large \\
\hline 2002. & 400 & 50 & 30 & 480 & 30 & 8 & 2 \\
\hline 2003. & 410 & 55 & 33 & 498 & 33 & 8.5 & 3 \\
\hline 2004. & 470 & 60 & 36 & 566 & 35 & 09 & 4 \\
\hline 2005 & 500 & 66 & 40 & 606 & 40 & 9.5 & 3 \\
\hline 2006 & 550 & 70 & 44 & 664 & 44 & 10 & 4 \\
\hline 2007 & 580 & 80 & 48 & 708 & 47 & 10 & 2 \\
\hline 2008 & 600 & 88 & 54 & 830 & 49 & 10.5 & 3 \\
\hline 2009 & 650 & 90 & 57 & 797 & 50 & 11 & 5 \\
\hline 2010 & 700 & 95 & 59 & 854 & 52 & 11.5 & 2 \\
\hline 2011 & 750 & 99 & 62 & 911 & 56 & 12 & 4 \\
\hline 2012 & 780 & 105 & 63 & 948 & 57 & 12 & 3 \\
\hline 2013 & 800 & 110 & 66 & 976 & 57 & 12.5 & 2 \\
\hline 2014 & 850 & 120 & 67 & 1037 & 58 & 12.75 & 4 \\
\hline 2015 & 900 & 125 & 69 & 1094 & 59 & 13 & 4 \\
\hline 2016 -May & 930 & 130 & 73 & 1133 & 60 & 13.25 & 3 \\
\hline
\end{tabular}

Source:Survey2002-2016

\begin{tabular}{|c|c|}
\hline \multirow{6}{*}{ Small } & \\
\hline & $=A$ \\
\hline & $=c$ \\
\hline & $\because$ \\
\hline & IF \\
\hline & $=M$ \\
\hline
\end{tabular}

Table2. NumberofEmployees(Situationat theend of period)

\begin{tabular}{|l|l|l|l|l|l|l|l|}
\hline & \multicolumn{3}{|l|}{ Averagenumberofemployees } & & & \multicolumn{2}{l|}{ Shareportionin \% } \\
\cline { 2 - 3 } \cline { 7 - 8 } & Small & Medium-sized & Large & & Small & Medium-sized & Large \\
\hline 2002. & 769 & 277 & 40 & 1086 & 31.65 & 20.00 & 48.35 \\
\hline 2003. & 972 & 328 & 76 & 1376 & 35.00 & 19.00 & 46.00 \\
\hline 2004. & 214 & 401 & 71 & 686 & 36.50 & 19.56 & 43.94 \\
\hline 2005 & 316 & 522 & 61 & 899 & 40.00 & 20.00 & 44.66 \\
\hline 2006 & 786 & 554 & 71 & 1411 & 41.00 & 21.00 & 45.90 \\
\hline 2007 & 765 & 576 & 67 & 1408 & 42.00 & 22.00 & 46.00 \\
\hline 2008 & 842 & 600 & 88 & 1530 & 43.00 & 23.00 & 44.00 \\
\hline 2009 & 888 & 611 & 84 & 1583 & 43.5 & 24.00 & 43.00 \\
\hline 2010 & 786 & 554 & 71 & 1411 & 41.00 & 21.00 & 45.90 \\
\hline 2011 & 786 & 554 & 71 & 1411 & 41.00 & 21.00 & 45.90 \\
\hline 2012 & 786 & 554 & 71 & 1411 & 41.00 & 21.00 & 45.90 \\
\hline 2013 & 786 & 554 & 71 & 1411 & 41.00 & 21.00 & 45.90 \\
\hline 2014 & 786 & 554 & 71 & 1411 & 41.00 & 21.00 & 45.90 \\
\hline 2015 & 786 & 554 & 71 & 1411 & 41.00 & 21.00 & 45.90 \\
\hline $2016-$ May & 786 & 554 & 71 & 1411 & 41.00 & 21.00 & 45.90 \\
\hline
\end{tabular}

\section{Source:Survey-2016}




\section{Average number of employees Small}

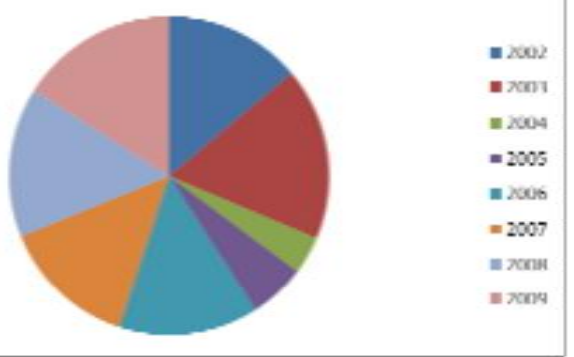

Table3.Thebasicfinancial indicesofJacobabad District entrepreneursbysize-class

\begin{tabular}{|c|c|c|c|c|c|c|c|c|c|}
\hline & \multicolumn{3}{|l|}{ Small } & \multicolumn{3}{|c|}{ Medium-sized } & \multicolumn{3}{|l|}{ Large } \\
\hline & & & $\begin{array}{l}\text { Financial } \\
\text { Result }\end{array}$ & & & $\begin{array}{l}\text { Financial } \\
\text { Result }\end{array}$ & & $1 \mathrm{ccc}$ & $\begin{array}{l}\text { Financial } \\
\text { Result }\end{array}$ \\
\hline A & 632.38 & 779.28 & -146.90 & 758.06 & 623.75 & 134.30 & 政 & & \\
\hline$B$ & 0.66 & & & & & & & & \\
\hline $\bar{C}$ & 61.68 & 313.04 & -251.36 & 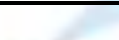 & & & & & \\
\hline $\bar{D}$ & 3719.48 & 4117.58 & -398.10 & 614.47 & 2580.74 & -1966.27 & 30031.09 & 11181.33 & 18849.76 \\
\hline $\bar{E}$ & & & & 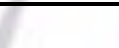 & & 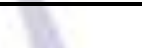 & 330.78 & & 330.78 \\
\hline $\bar{F}$ & 1178.54 & 1074.41 & 104.12 & 620.27 & 0.00 & 620.27 & 3072.18 & & 3072.18 \\
\hline $\bar{G}$ & 7247.29 & 19294.78 & -12047.49 & 2174.52 & 295.63 & 1878.89 & 10592.39 & 591.59 & 10000.80 \\
\hline$\overline{\mathrm{H}}$ & 124.35 & 675.98 & -551.63 & & 1531.20 & -1531.20 & 0.00 & & \\
\hline $\mathrm{I}$ & 582.80 & 327.79 & 255.01 & 69.31 & 564.07 & -494.76 & 248.54 & & 248.54 \\
\hline $\mathrm{J}$ & 437.56 & 8440.42 & -8002.86 & 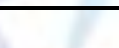 & 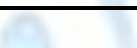 & & & & \\
\hline $\bar{K}$ & 3955.92 & 1636.82 & 2319.10 & 688.58 & 20765.30 & -20076.71 & & & \\
\hline $\bar{M}$ & 75.61 & 4.81 & 70.80 & . & 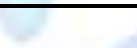 & 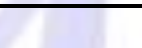 & & & \\
\hline $\mathrm{N}$ & 14.26 & 0.17 & 14.09 & 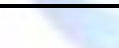 & & & & & \\
\hline $\mathrm{O}$ & 687.59 & 262.47 & 425.12 & 7.63 & & 7.63 & 125.68 & & 125.68 \\
\hline Total & 18718.12 & 36927.54 & -18210.09 & 4932.84 & 26360.69 & -21435.48 & 44400.66 & 11772.92 & \\
\hline
\end{tabular}

1. Source:Survey-2009

2. Code:A-agriculture,huntingandforestry;B-fishing;C- miningandquarrying;D- manufacturing;E-Electricity,gasandwater supply; F-construction;G-wholesaleandretailtrade,repairof motorvehicles, motorcyclesandpersonalandhouseholdgoods; $\mathrm{H}-\mathrm{hotels}$ andrestaurants;I- transport,storageandcommunication;J-financialintermediation;K -realestate,rentingandbusinessactivities; $\mathrm{L}-$ publicadministrationanddefense,compulsorysocialsecurity;M-education; $\mathrm{N}$-healthandsocialwork;O-othercommunity,socialand personalserviceactivities

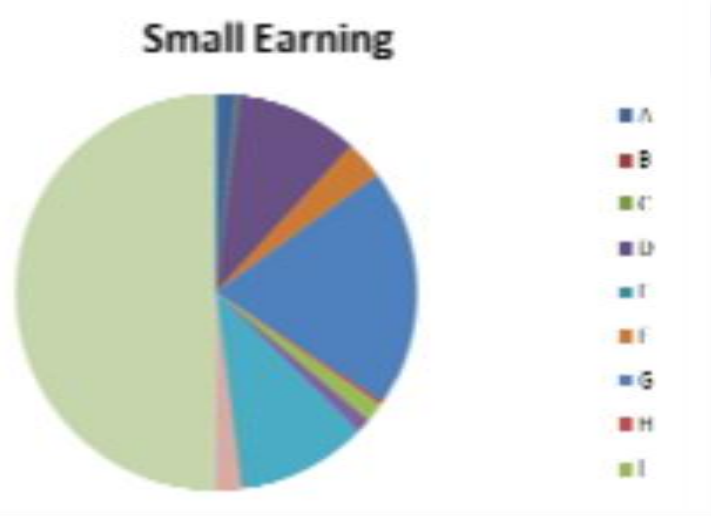


Table5.Income generatedabroad bysize-classofEnterprisesin 2009

\begin{tabular}{|l|l|l|l|l|l|l|}
\hline & & & & \multicolumn{3}{l}{ Shareportionin\% } \\
\cline { 5 - 7 } & & & & Large & Medium-sized & Small \\
\hline $\mathrm{A}$ & 108.93 & & & 0.04 & & \\
\hline $\mathrm{B}$ & & & & & & \\
\hline $\mathrm{C}$ & & & & & & \\
\hline $\mathrm{D}$ & 8123.73 & 3426.51 & 228561.87 & 2.90 & 1.22 & 81.68 \\
\hline $\mathrm{E}$ & & & & & & \\
\hline $\mathrm{F}$ & 405.89 & 462.26 & 877.77 & 0.15 & 0.17 & 0.31 \\
\hline $\mathrm{G}$ & 15378.33 & 2891.13 & 9806.15 & 5.50 & 1.03 & 3.50 \\
\hline $\mathrm{H}$ & 62.67 & 6.96 & & 0.02 & & \\
\hline $\mathrm{I}$ & 2887.31 & 2985.97 & 1559.06 & 1.03 & 1.07 & 0.56 \\
\hline $\mathrm{J}$ & & & & & & \\
\hline $\mathrm{K}$ & 1426.41 & 519.96 & & 0.51 & 0.19 & \\
\hline $\mathrm{M}$ & & & & & & \\
\hline $\mathrm{N}$ & & & & & & \\
\hline $\mathrm{O}$ & 210.74 & 112.75 & & 0.08 & 0.04 & \\
\hline Total & 28604.02 & 10405.53 & 240804.84 & 10.22 & 3.72 & \\
\hline
\end{tabular}

\section{Source:Survey-2016}

Code:A-agriculture,huntingandforestry;B-fishing;C- miningandquarrying;D- manufacturing;E-Electricity,gasandwatersupply; Fconstruction; $\quad G$-wholesaleandretailtrade,repairof motorvehicles,motorcyclesandpersonalandhouseholdgoods; $\mathrm{H}$-hotelsand restaurants;I-transport,storage andcommunication;J-financialintermediation;K-realestate, renting andbusiness activates;L-public administrationanddefense,compulsorysocialsecurity;M-education; $\mathrm{N}$-healthandsocialwork;O-othercommunity,socialandpersonal serviceactivities

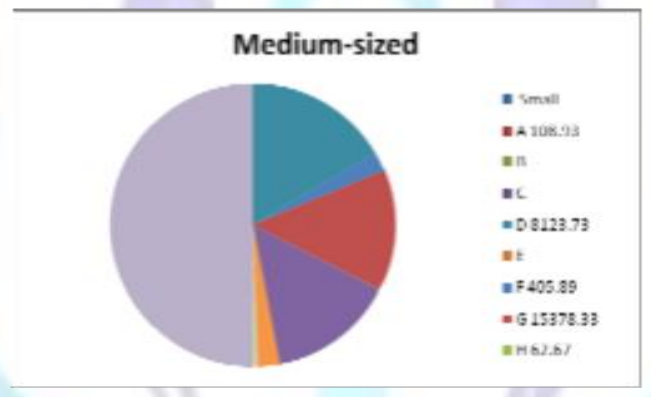

Table 6.PrerequisitesofSMEs development inJacobabad(entrepreneur perspective)

\section{Source:Survey-2009}

\begin{tabular}{|l|l|}
\hline Prerequisite & Mean \\
\hline Corruptionelimination & 4.68 \\
\hline Reductionofinformaleconomy & 4.67 \\
\hline Differentandnumerousfinancialsources & 4.35 \\
\hline Easierloanprocedures & 4.27 \\
\hline Localgovernmentconcern & 4.24 \\
\hline Cooperationamongentrepreneurs & 4.13 \\
\hline Stategovernmentconcern & 4.13 \\
\hline Protectionfromforeigncompetition & 3.75 \\
\hline
\end{tabular}

\section{Results and Discussions}

Effect of microfinance on destitution There is a sure measure of level headed discussion about whether sway evaluation of microfinance tasks is essential or not as indicated by Simanowitz (2001b). The contention is that if the business sector can give satisfactory proxies 10 to effect, demonstrating that customers are glad to pay for an administration, appraisals are a misuse of assets (on the same page.). Nonetheless, this is excessively oversimplified a justification as business sector intermediaries cover the extent of customer reactions and advantages to the MFI (on the same page.) Therefore, affect evaluation of microfinance intercessions is vital, not simply to exhibit to contributors that their mediations are having a positive effect, however to take into 
consideration learning inside MFIs with the goal that they can enhance their administrations and the effect of their ventures (Simanowitz, 2001b, p.11).

The impacts of miniaturized scale credit Programs on takes an interest can be measured as far as utilization, sustenance, occupation, total assets, tutoring, contraception utilized and ripeness. An overview was completed and relapse method was utilized to break down the effect of smaller scale credit on members in Bangladesh.

On the off chance that the Micro Finance Bank is to have sought effect on destitution lessening in Pakistan there is a requirement for extension of smaller scale credit administrations to poor people. In such manner, miniaturized scale account bunch which contains 8 surely understood NGOs in Pakistan indicated enthusiasm for beginning a small scale fund organization which would give preparing to all experts that would help with embracing standard money related practices. Additionally miniaturized scale money Bank ought to concentrate on teaching funds propensities in the poor so as to boost the effect on destitution diminishment. Though Pakistan does not have a broad society of small scale credit the intention of the present government to set up a Micro credit Bank can go far in expanding the welfare of poor people. Acquiring from casual source does not have a practical welfare expanding impact on the poor family unit. The two phase gauge did by Shahid-ur-R-Khandker and Rashidur-R-Farquee demonstrate that both casual and formal credit it positively affect family unit per capital yearly utilization if there should be an occurrence of Pakistan.

\section{Conclusion}

Pakistan is faced with twin challenges of reviving growth and reducing poverty. Poverty alleviation thus has to be effected not only through microeconomic policy, but also by bringing about significant improvement in the structure and functioning of system of governance \& organized mechanism of micro-credit to reach over million targeted people by the end of 2007 . The case study indicates that $40 \%$ of the beneficiaries opened shops/small provision stores, followed by investment in poultry, embroidery and livestock. The paper also provides some technical information on profitability/cost benefit analysis of income generating activities/trades in rural Pakistan

During research it was observed that Poor governance is the key underlying cause of poverty as it not only enhances vulnerability but is the cause of low business confidence which translates into lower investment levels; reduced efficiency and provision of services which has serious implications for human development; and deterioration in law \& order situation which effects both economic activity and quality of life and in this way government should held all these things in check while devising poverty reduction strategy through spreading network of micro-credit Finance institutions across the country.

\section{REFERENCES}

1. Akbar Zaidi (2005-06) "issues in Pakistan's Economy" Oxford University Press.

2. World Development Indicators (2004-05) World Bank Publications Washington D.C

3. Social Development in Pakistan annual Review 2000 towards poverty reduction Oxford University Press.

4. Pakistan National Human Development Report 2003 poverty, growth and governance by Akmal Hussain.

5. Micro-credit financing: fighting against poverty? Research report Social Policy Development Center by Hari R.Lohano \& Haroon Jamal (2003)

6. Fighting poverty with Micro credit-Experience in Bangladesh by Shahidur R.Khandker -The University Press Limited 1999.

7. The Micro credit Program of OPP-Orangi Charitable Trust by Aquila Ismail (published in 2005)

8. Micro creditfor Development -the impact o OPP-Orangi Charitable Trust Micro credit Program on Urban Livelihoods by S.Akbar Zaidi (City Press) Karachi.

9. Role of Micro Credit in Economic Revival and poverty Alleviation - The institute of Bankers Pakistan

10. Who needs Credit? Poverty and finance in Bangladesh Edited

By Geoffrey D Wood \& Iffath A Sharif

(The United Press Limited) 
11. Banker to the poor- The autobiography of Muhammad Yunus, founder of the Grameen Bank By Muhammad Yunus with Alan Jolis (The United Press Limited 2001).

12. Beyond Micro -Credit-putting Development back in to microfinance by Thomas Fishei \& M.S Sriram \& et al.

13. Poverty in Pakistan issues, Causes and Institutional Responses Asian Development Bank

14. Finance at the Frontier- Debt Capacity and the Role of Credit in the Private Economy by J.D Von Pischke (Economic Development Institute of the World bank)

15. Role of Banks for poverty alleviation by Dr. Kali Mohan Bhattacharya (2002)

16. Rural Banking in India by S.S.M Desai

17. Reflections on Human Development by Dr Mahbub- ul-Haq 19 Power \& Civil Society in Pakistan by Weis Gilani 20 Making Services work for poor people

(World Development Report 2004 by World Bank)

21. Pakistan -The Economy of an Elitist state by Dr Ishrat Hussain

22.Poverty reduction and the role of institutions in developing Asia. -Asian Development Bank (2002)

23. The Economics of Microfinance.

Beatriz Aremendariz de Aghion \& Jonatan Morduch (2005).

24. Resource Distribution \& Poverty Reduction in Pakistan.

Edited by Sikandar Brohi. (SZABIST-2004) 